\title{
Erratum to: Community, Authorities, and Support for Vigilantism: Experimental Evidence
}

\author{
Daniel Zizumbo-Colunga ${ }^{1}$
}

\section{Erratum to: Polit Behav \\ DOI 10.1007/s11109-017-9388-6}

The original version of this article unfortunately contained a mistake. The values in the Fig. 1 have been erroneously converted as VALOR during the production process. The corrected Fig. 1 is given below.

The original article has been corrected.

The online version of the original article can be found under doi:10.1007/s11109-017-9388-6.

Daniel Zizumbo-Colunga

daniel.zizumbo@cide.edu

1 Drug Policy Program, Center for Research and Teaching in Economics, National Council of Science and Technology, Circuito Tecnopolo Norte 117, Tecnopolo Pocitos II, 20313 Aguascalientes, AGS, Mexico 
Fig. 1 Differences between my experimental sample and a random sample from the Mexican population * Source 2012 AmericasBarometer by the Latin American Public Opinion Project (LAPOP), www.

LapopSurveys.org

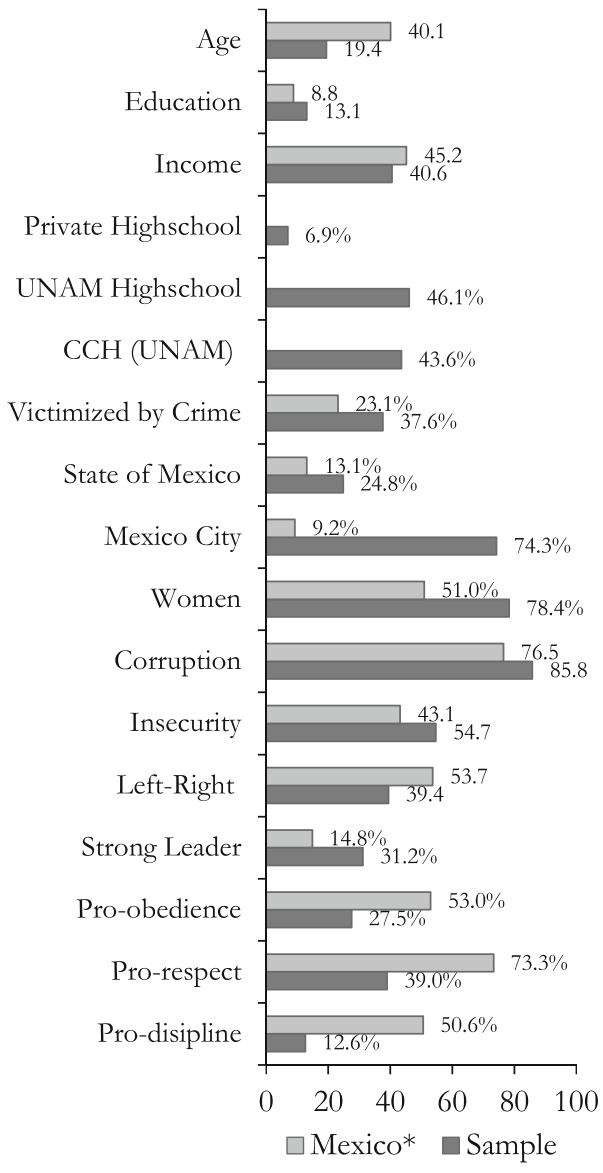

